Epidemiology

\section{Cancer incidence in airline cabin crew}

\section{E A Whelan}

\section{Evidence that flight crew are at increased risk for certain types of cancer is growing although epidemiological evidence remains inconclusive}

$\mathrm{R}$ ecent reports highlighting increased cancer incidence and mortality among airline pilots and cabin crew have raised concerns about potential exposure of these workers to known or suspected carcinogens, in particular cosmic ionising radiation. Higher radiation dose rates are found at higher altitudes and in the polar regions, and mean doses to flight crew have been increasing over time as longer flights at higher altitudes have become more frequent. Other possible hazards that may play a role in cancer risk for flight crew include irregular working hours and disturbances of circadian rhythm. Epidemiological studies of mortality and cancer incidence in flight crew have been reviewed recently, ${ }^{12}$ but in the past $2-3$ years, 10 new studies of pilots or cabin crew have been published, the majority of which result from a combined effort underway by the European Community. These studies include three mortality studies ${ }^{3-5}$ and seven cancer incidence studies. ${ }^{6-12}$ Overall, the reports suggest that pilots are at increased risk of malignant melanoma, non-melanoma skin cancer, and possibly acute myeloid leukemia, and that cabin crew are at increased risk for breast cancer and malignant melanoma. However, the question remains as to whether the observed excesses are due to occupational exposures or nonoccupational factors, such as reproductive history and lifestyle. Studies of cabin crew have been limited by exposure assessment that is based on data readily available from employment records such as duration of employment, domestic or international status, or employment before or after the operation of jet aircraft. In contrast, most recent studies of pilots have estimated radiation dose from cumulative aircraft-specific block hours. Most of the studies have taken advantage of existing national record systems for cancer information, but are limited in their ability to take into account the well established non-occupational risk factors for the cancers of interest. Yet despite these limitations, the studies are remarkably consistent in providing

evidence of increased risk for these cancers.

\begin{abstract}
"There is mounting evidence that cabin crew appear to have an increased risk of malignant melanoma and breast cancer"
\end{abstract}

Two reports in this issue of Occupational and Environmental Medicine take advantage of comprehensive population registries in Iceland and Sweden and add to the mounting evidence that cabin crew appear to have an increased risk of malignant melanoma and breast cancer. The study by Rafnsson et al of Icelandic cabin $\mathrm{crew}^{13}$ is the first published case-control investigation of breast cancer among flight attendants where a concerted attempt was made to adjust for possible confounding by reproductive factors. Even with a small number of cases, the investigators were able to show a significant link between length of employment and risk of breast cancer. It is interesting that the increased risk was associated with length of employment prior to 1971, before the operation of jet aircraft which fly at higher altitudes and are therefore subject to higher levels of cosmic radiation. However, even at lower altitudes, Icelandic cabin crew fly more northerly flight profiles which are associated with higher exposure to cosmic radiation. The authors note that their findings are consistent with the long induction period that may be required for breast cancer. An unusual aspect of this study is the fact that parity and age at first childbirth have a patten of risk for breast cancer that is the inverse of what is generally observed in the literature. This finding argues for further characterisation of these risk factors in this occupational group.

The report by Linnersjö et al describes a nested case-control study among Swedish cabin crew with a focus on both breast cancer and malignant melanoma. ${ }^{14}$ Incidence rates for malignant melanoma were 2-3 times the expected rate for both men and women. Female cabin attendants had a 30\% increase in breast cancer incidence. These investigators made an effort to improve on previous studies by characterising exposure in terms of cumulative block hours flown by aircraft type. "Block" time is the time from origin gate to destination gate, including both airborne and taxi time. Company flight histories typically contain block time rather than airborne time. Unlike the study by Rafnsson et al, this study found no clear evidence of a link between length of employment and cancer incidence, nor was there an association between cumulative block hours and cancer incidence. The investigators estimated that the reproductive history pattern in female cabin crew (that is, fewer pregnancies later in life) could yield about a $10 \%$ increase in breast cancer incidence compared to the general population, which does not appear to fully explain the excess.

\section{"Detailed information about expo- sure and potential confounding fac- tors is required"}

These results highlight the need for studies that are able to obtain detailed information about exposure and potential confounding factors. In addition to reproductive factors, information about family history of cancer, sunlight exposure, and socioeconomic status would help sort out the role that non-occupational factors may have in these diseases. Many investigators have emphasised the issue of socioeconomic status and the potential for detection bias when comparing flight crew to the general population since flight crew are likely to receive more regular medical screening. This problem is minimised in studies where internal comparisons of well characterised exposure categories are the main focus. Consistent reports of an increased risk for malignant melanoma among air crew underscore the importance of addressing the potential contribution of lifestyle factors, such as sunlight exposure. The study by Rafnsson et al in this issue of the journal $^{15}$ is the first to attempt to estimate, for air crew studies, the extent of confounding that may be due to nonoccupational risk factors for melanoma. The method used relies on the availability of published, valid estimates of the relative risks associated with sunlight exposure and other known risk factors for melanoma.

Current research on cancer in flight crew will provide much needed information. The ongoing research is primarily being conducted by two groups, one in Europe and one in the USA. Supported by the European Commission, nine countries are participating in a joint European cohort mortality 
study which uses a common study design, facilitating a pooled analysis of the data. This study of over 22000 cockpit crew and 50000 cabin crew will be the most powerful to date to evaluate cancer mortality associated with these occupations. Although no individualised exposure measurements are available, an exposure assessment based on flight hours and estimated dose rates by aircraft type will be utilised. Many of the individual countries participating in the pooled analysis have published cancer incidence studies of pilots and/or cabin crew; the reports published in this issue are two such studies. The US National Institute for Occupational Safety and Health (NIOSH) has recently initiated a breast cancer incidence study among 9000 flight attendants. This study is the first to collect information about nonoccupational risk factors, routes flown, and employment at other airlines from former flight attendants or their nextof-kin. A second study underway at NIOSH is addressing potential DNA damage resulting from ionising radiation exposure among pilots who flew predominantly long-haul flights for most of their career. This biodosimetry study will examine whether persistent chromosomal aberrations can be linked specifically to cosmic radiation exposure as distinct from lifestyle, dietary, or environmental factors. With recent evidence showing increases in cancer risk among individuals with high levels of chromosomal aberrations, this study may shed light on the potential mechanism behind the hypothesised link between cosmic radiation and cancer.

The evidence that flight crew are at increased risk for certain types of cancer is growing and current concerns about potential hazards in this occupation are not without basis. However, thus far, the epidemiological evidence remains inconclusive due to limitations in exposure assessment, sample size, and characterisation of confounders. The studies from the European Union and the USA will move us further towards understanding the nature of the risks involved for workers in this unique occupation.

Occup Environ Med 2003;60:805-806

Correspondence to: Dr E A Whelan, 4676

Columbia Parkway, R-15 Cincinnati, OH, USA: ewhelan@cdc.gov

\section{REFERENCES}

1 Boice JD, Blettner M, Auvinen A. Epidemiologic studies of pilots and aircrew. Health Phys 2000:79:576-84

2 Ballard T, Lagorio S, De Angelis G, et al. Cancer incidence and mortality among flight personnel: $a$ meta-analysis. Aviat Space Environ Med 2000;71:216-24.

3 Blettner M, Zeeb H, Langner I, et al. Mortality from cancer and other causes among airline cabin attendants in Germany, 1960-1997. Am J Epidemiol 2002;156:556-65.
4 Zeeb H, Blettner M, Hammer GP, et al. Cohort mortality study of German cockpit crew, 19601997. Epidemiology 2002;13:693-9.

5 Ballard T, Lagorio S, De Santis M, et al. A retrospective cohort mortality study of Italian commercian airline cockpit crew and cabin attendants, 1956-96. Int J Occup Environ Health 2002;8:87-96

6 Pukkala E, Aspholm R, Auvinen A, et al. Incidence of cancer among Nordic airline pilots over five decades: occupational cohort study. BMJ 2002:325:567.

7 Haldorsen T, Reitan JB, Tveten U. Cancer incidence among Norwegian airline pilots. Scand J Work Environ Health 2000;26:106-11.

8 Haldorsen T, Reitan JB, Tveten U. Cancer incidence among Norwegian airline cabin attendants. Int J Epidemiol 2001;30:825-30.

9 Reynolds P, Cone J, Layefsky M, et al. Cancer incidence in California flight attendants (United States). Cancer Causes Control 2002; 13:317-24.

10 Rafnsson V, Hrafnkelsson J, Tulinius $\mathrm{H}$. Incidence of cancer among commercial airline pilots. Occup Environ Med 2000;57:175-9.

11 Rafnsson V, Tulinius H, Jonasson JG, et al. Risk of breast cancer in female flight attendants: a population-based study. Cancer Causes Control $2001 ; 12: 95-101$

12 Hammar $\mathbf{N}$, Linnersiö, Alfredsson L, et al. Cancer incidence in airline and military pilots in Sweden 1961-1966. Aviat Space Environ Med 2002;73:2-7.

13 Rafnsson V, Sulem P, Tulinius H, et al. Breast cancer risk in airline cabin attendants: a nested case-control study in Iceland. Occup Environ Med 2003:60:807-9.

14 Linnersiö A, Hammar N, Dammström B-G, et al. Cancer incidence in airline cabin crewexperience from Sweden. Occup Environ Med 2003;60:810-14.

15 Rafnsson V, Hrafnkelsson J, Tulinius H, et al. Risk factors for cutaneous malignant melanoma among aircrews and a random sample of the population. Occup Environ Med 2003;60:815-20.

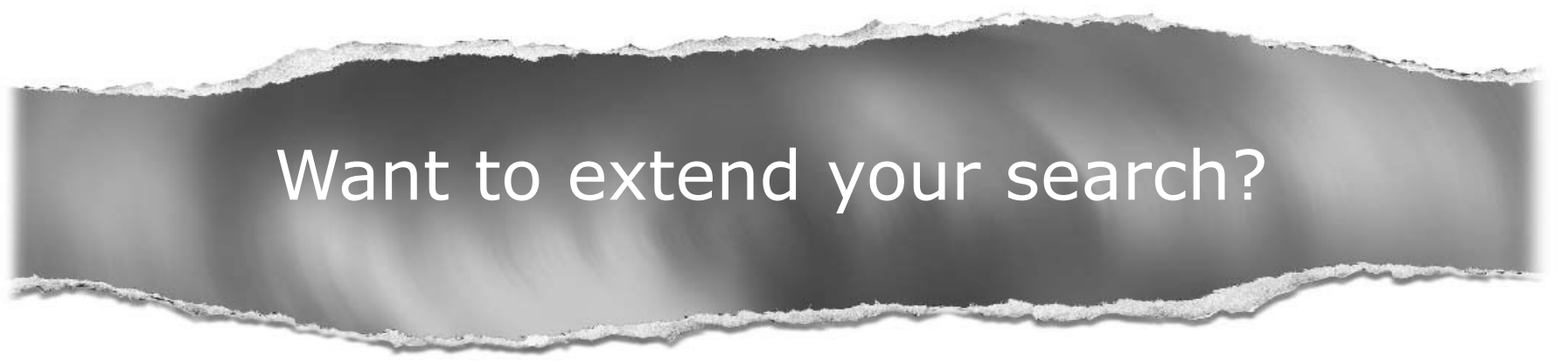

Cross journal searching

Can't find what you're looking for in Occupational and Environmental Medicine? Extend your search across 340+ journals. Search restriction options include specific subject areas (eg. clinical medicine, basic research), select specific journals or search all available titles. 